\title{
Organic Fungicides with Adjuvants in the Prevention of Diseases at Wheat
}

\author{
Silvio D. Ferreira ${ }^{1}$, Adriana C. Salvalaggio ${ }^{1}$, Jaqueline de A. Barbosa ${ }^{1} \&$ Neumarcio V. da Costa $^{1}$ \\ ${ }^{1}$ School of Agronomy, State University of the West of Paraná, Marechal Cândido Rondon, Brazil \\ Correspondence: Jaqueline de A. Barbosa, School of Agronomy, State University of the West of Paraná, Trinta e \\ um de Março Street, 1610, Marechal Cândido Rondon, Brazil. Tel: 55-45-99916-1143. E-mail: \\ jaquelineabarbosa@hotmail.com
}

$\begin{array}{lc}\text { Received: August 28, } 2017 & \text { Accepted: October 10, } 2017 \quad \text { Online Published: November 15, } 2017 \\ \text { doi:10.5539/jas.v9n12p223 } & \text { URL: https://doi.org/10.5539/jas.v9n12p223 }\end{array}$

\begin{abstract}
The efficiency of fungal solutions, without wheat in organic systems, can be improved with the use of adjuvants. The objective of this study was to evaluate the dispersion of fungal droplets of organic fungicides with adjuvants in wheat leaves and disease control efficiency. The experimental design used was the completely randomized design in factorial scheme $2 \times 3$, with 6 repetitions. The first factor corresponded to fungal solutions bordeaux syrup $\left(200 \mathrm{~g} \mathrm{~L}^{-1}\right)$ and lime sulfur syrup $\left(200 \mathrm{~g} \mathrm{~L}^{-1}\right)$ and second factor to the adjuvants: mineral oil and vegetable oil $\left(0.5 \% \mathrm{v} \mathrm{v}^{-1}\right)$ and one Witness without application.. On the adaxial side, the use of the mineral oil provided scatter of drop 111.8 and $25.7 \%$ higher, to the grouts without adjuvants and vegetable oil, respectively. The greater spreading of the droplets on the two foliar faces and a lower incidence of the diseases with the product of the lime sulfur syrup + mineral oil. The use of the adjuvants in the syrups evaluated with positive results in the production components, standing out the mineral oil.
\end{abstract}

Keywords: Triticum aestivum L., natural syrups, application technology, droplet deposition

\section{Introduction}

The wheat (Triticum aestivum L.) stands out as the second most produced cereal in the world. In Brazil, approximately $90 \%$ of the planted area is located in the south region, with the state of Paraná being the largest producer with more than 3 million tons (CONAB, 2017).

However, a wheat crop as a winter crop is characterized by being susceptible to the occurrence of fungal diseases that cause losses in yield of up to $42 \%$ (Oliveira et al., 2013). Among the main fungal diseases, the leaf rust (Puccinia triticina) as well as the leaf spot (Drechslera tritici-repentis) (Lenz, Costa, Coradini, Dressler, \& Mellho, 2011).

The control of wheat diseases must adopt integrated practices such as, sowing at the appropriate time, use of resistant cultivars as well as the application of fungicides chemical control) (Tormen et al., 2013). However, chemical control has been the main method used in the management of diseases in wheat (Souza et al., 2014).

Due to the growing concern with poisoning due to the use of agrochemicals, the growing demand for healthier foods and the need to reduce production costs, the use of natural pesticides such as bordeaux syrup and lime sulfur syrup has been advocated.

The results observed with the use of natural syrups have provided yields ranging from 86.7 to $93.3 \%$ over the conventional system and control efficacy control greater than $60 \%$ depending on the culture (Rodrigues, Nakada, Silva, Dantas, \& Santos, 2006; Carvalho, Wanderley, \& Oliveira, 2010).

However, the scientific studies that evaluate the use, the efficiency and the control the fungal diseases of syrups in the wheat crop are rare. And when it is intended to combine the organic syrups with spreading oils, no information was found in the literature.

The addition of oils to the spraying syrup may improve the product activity or application characteristics, because the oils favor the scattering of the syrups, reducing the surface tension, providing greater wetting of the leaf surfaces (Aguiar-Júnior et al., 2011; Silva-Matte et al., 2014). In this way, it can raise an absorption of the syrups, with the possibility of reducing the use of pesticides, becoming economically viable. 
Therefore, the hypotheses were based on the premise that the use of adjuvants with organic fungicides of contact can improve the spreading of the drop on the leaf surface of wheat and consequently the efficiency of control. The objective of this work is to evaluate the spreading of organic fungicide syrup droplets with adjuvants in wheat leaves and in all diseases control.

\section{Material and Methods}

The experiment was conducted in pots, maintained in field condition. The climate of the region, according to a classification of Köppen, presents with rains well distributed during the year, hot summers, winters with frost infrequent, with precipitation and average annual temperature of $1,500 \mathrm{~mm}$ and $21.4{ }^{\circ} \mathrm{C}$ respectively.

The experimental design used was the completely randomized design in factorial scheme $2 \times 3$, with 6 repetitions. The first factor corresponded to fungal solutions bordeaux syrup $\left(200 \mathrm{~g} \mathrm{~L}^{-1}\right)$ and lime sulfur syrup $\left(200 \mathrm{~g} \mathrm{~L}^{-1}\right)$ and second factor corresponded to treatments with and without the addition of vegetable oil (Natur'l oil) and mineral oil (Nimbus $\left.{ }^{\circledR}\right)$ a $0.5 \% \mathrm{v} \mathrm{v}^{-1}$ of the product.

The soil used as substrate was classified as Red Eutrophic Latossolo (clay texture) (SANTOS et al., 2013), with the following chemical characteristics: $\mathrm{pH}=5.26\left(\mathrm{CaCl}_{2}\right) ; 3.24 \mathrm{cmol}_{\mathrm{c}} \mathrm{dm}^{-3} \mathrm{H}+\mathrm{Al} ; 4.37 \mathrm{cmol}_{\mathrm{c}} \mathrm{dm}^{-3} \mathrm{Ca}^{2+} ; 1.56$ $\mathrm{cmol}_{\mathrm{c}} \mathrm{dm}^{-3} \mathrm{Mg}^{2+} ; 0.35 \mathrm{cmol}_{\mathrm{c}} \mathrm{dm}^{-3} \mathrm{~K}^{+} ; 4.82 \mathrm{mg} \mathrm{dm}$ of P; $10.25 \mathrm{~g} \mathrm{dm}^{-3}$ of MO; SB of $6.28 \mathrm{cmol}_{\mathrm{c} \mathrm{dm}} \mathrm{d}^{-3}$; CTC of $9.52 \mathrm{cmol}_{\mathrm{c}} \mathrm{dm}^{-3}$ and $\mathrm{V}$ of $65.97 \%$.

The wheat (Triticum aestivum L.) cultivar CD 150, seeded in pots of $12 \mathrm{dm}^{-3}$ was used. At 14 days after the germination (DAG) of the wheat was planned for the standardization of the density of 4 plants vaso ${ }^{-1}$.

The application of the fungicides in the plants was carried out twice, with interval of 15 days. The first application was at 60 days after sowing (DAS), the second at 75 DAS at grain filling.

The spraying of the fungicides was realized with the aid of a $\mathrm{CO}_{2}$ pressurized costal sprayer equipped with bar placed to $50 \mathrm{~cm}$ tall in relation to plants, provided with four flat jet tips (Model Magno ADGA 11002), spaced 50 $\mathrm{cm}$ apart each other, with a constant pressure of $2.2 \mathrm{kgf} \mathrm{cm}^{2}$ and a syrup volume equivalent to $200 \mathrm{~L} \mathrm{ha}^{-1}$.

The first application was performed between $17 \mathrm{~h}$ and $17 \mathrm{~h} 30 \mathrm{~min}$, and the climatic condition at the time of application was average temperature of $23.2{ }^{\circ} \mathrm{C}$, one relative humidity one of $65 \%$ and wind $4.3 \mathrm{~km} \mathrm{~h}^{-1}$. The second application it was performed between $16 \mathrm{~h}$ and $17 \mathrm{~h} 15 \mathrm{~min}$, with an average temperature of $22.7^{\circ} \mathrm{C}$, and humidity relative to the $58 \%$ and wind $3.7 \mathrm{~km} \mathrm{~h}^{-1}$.

For the determination of the surface tension of the solutions, it was used a methodology adapted from Teixeira Neto, Malta, and Santos (2009), being the set of 8 drops of each solution evaluated as a repetition. During the experiment the laboratory ambient temperature was $18 \pm 8{ }^{\circ} \mathrm{C}$ and relative humidity between $60 \%$, monitored every hour with the aid of the thermometer, model MTH-1362W (Minipa).

Before the first application, it was verified the scattering of the drop (cm2) in the foliar faces: abaxial and adaxial of the leaves of wheat. The first undiluted expanded sheet below the flag sheet was removed for evaluation.

An adhesive tape was used to attach the wheat leaves to a white acrylic plate of A4 size. Subsequently, with the help of a micropipette, calibrated to a volume of $12 \mu \mathrm{L}$, drops of the solutions were applied to the foliar faces. Immediately after drop deposition, the leaves were photographed with the aid of a digital camera (Samsung ${ }^{\circledR}$ HD ST77 with 16.1 mega pixels). For image analysis, was used Quant V 1.0 software (Vale, Fernandes Filho, \& Liberato, 2003).

At 7, 14 and 21 days after application of the treatments were evaluated the incidence of rust and incidence of leaf smudge based on the methodology adapted from Souza et al. (2014). After the harvest, the dry mass of the plants (g), the number of seeds per spike (no spike ${ }^{-1}$ ). To determine the mass of thousand grains (g), the humidity was corrected to $13 \%$.

The data were submitted to analysis of variance, and the averages were compared by Tukey test $(p \leq 0.05)$, using SISVAR software (Ferreira, 2011).

\section{Results and Discussion}

The results observed in the analysis of variance show a significant interaction between the fungicide solutions (bordeaux syrup and lime sulfur syrup) and the treatments (without and with mineral and vegetable oil) for the surface tension of the drops, incidence of leaf spot, number of grains per spike and mass of one thousand grains (Table 1). 
The adjuvants provided a reduction in the surface tension of the syrups (Table 2). Mineral oil and vegetable oil added to the bordeaux mixture reduced surface tension by $45.4 \%$ and $31.4 \%$, respectively. On the other hand, the mineral oil and vegetable oil added to the lime sulfur syrup reduced 46.1 and $34.9 \%$, respectively.

The bordeaux syrup presented lower surface tension, $2 \%$ lower than the lime surfer syrup. No statistical difference was observed for both syrups when mineral oil was added, while vegetable oil was more efficient in reducing the surface tension when added to the lime surfer syrup.

Table 1. Mean squares of the analysis of variance and coefficient of variation of the variables evaluated in the experiment

\begin{tabular}{lllll}
\hline Variables & Syrup $(\mathrm{S})$ & Adjuvant $(\mathrm{A})$ & $\mathrm{S} \mathrm{x} \mathrm{A}$ & $\mathrm{CV}(\%)$ \\
\hline Surface tension of the drople $\left(\mathrm{mN} \mathrm{m}^{-1}\right)$ & $0,0076^{\mathrm{NS}}$ & $3426,9628 * *$ & $6,9919^{* *}$ & 2,26 \\
Spreading of the adaxial surface $\left(\mathrm{cm}^{2}\right)$ & $0,0002^{\mathrm{NS}}$ & $0,0668 * *$ & $0,0002^{\mathrm{NS}}$ & 6,83 \\
Spreading of the abaxial surface $\left(\mathrm{cm}^{2}\right)$ & $0,0008^{*}$ & $0,0810 * *$ & $0,0007^{\mathrm{NS}}$ & 5,37 \\
\hline Incidence of rust $(\%)$ & $5,4444^{* *}$ & $19,4445 * *$ & $0,1111^{\mathrm{NS}}$ & 7,72 \\
Incidence of leaf smudge (\%) & $0,4444^{\mathrm{NS}}$ & $34,6944 * *$ & $3,0277 * *$ & 8,96 \\
\hline Dry mass of the plants (g) & $10,7256^{\mathrm{NS}}$ & $38,5586 * *$ & $0,2640^{\mathrm{NS}}$ & 16,46 \\
Number of seeds per spike (unit.) & $115,9570 * *$ & $521,6641 * *$ & $17,4730 * *$ & 5,09 \\
Mass of thousand grains (g) & $29,6661 * *$ & $18,6405 * *$ & $2,0285 * *$ & 1,90 \\
\hline
\end{tabular}

Note. ${ }^{*}$ and ${ }^{* *}$ significant at the level of 5 and $1 \%$ probability, respectively. ${ }^{\mathrm{NS}}$ not significant.

Table 1. Medium values of surface tension of bordeaux syrup and lime sulfur syrup with and without mixtures with mineral and vegetable oil and spreading of the drop $\left(\mathrm{cm}^{2}\right)$ on the adaxial and abaxial side of wheat leaves

\begin{tabular}{|c|c|c|c|c|}
\hline \multirow{2}{*}{ Syrup } & \multicolumn{4}{|c|}{ Surface tension $\left(\mathrm{mN} \mathrm{m}^{-1}\right)$} \\
\hline & Without adjuvant & Mineral oil & Vegetable oil & Mean \\
\hline Bordeaux syrup & $70,814 \mathrm{Ba}$ & $38,686 \mathrm{Ac}$ & $48,586 \mathrm{Ab}$ & 52,695 \\
\hline Lime sulfur syrup & $72,235 \mathrm{Aa}$ & $38,956 \mathrm{Ac}$ & $46,982 \mathrm{Bb}$ & 52,725 \\
\hline Mean & 71,525 & 38,821 & 47,784 & \\
\hline \multirow{2}{*}{ Syrup } & \multicolumn{4}{|c|}{ Spreading of the adaxial surface $\left(\mathrm{cm}^{2}\right)$} \\
\hline & Without adjuvant & Mineral oil & Vegetable oil & Mean \\
\hline Bordeaux syrup & 0,134 & 0,275 & 0,218 & $0,209 \mathrm{~A}$ \\
\hline Lime sulfur syrup & 0,130 & 0,286 & 0,228 & $0,214 \mathrm{~A}$ \\
\hline Mean & $0,132 \mathrm{c}$ & $0,280 \mathrm{a}$ & $0,223 \mathrm{~b}$ & \\
\hline \multirow{2}{*}{ Syrup } & \multicolumn{4}{|c|}{ Spreading of the abaxial surface $\left(\mathrm{cm}^{2}\right)$} \\
\hline & Without adjuvant & Mineral oil & Vegetable oil & Mean \\
\hline Bordeaux syrup & 0,131 & 0,291 & 0,233 & $0,219 \mathrm{~B}$ \\
\hline Lime sulfur syrup & 0,137 & 0,300 & 0,249 & $0,229 \mathrm{~A}$ \\
\hline Mean & $0,134 \mathrm{c}$ & $0,296 \mathrm{a}$ & $0,241 \mathrm{~b}$ & \\
\hline
\end{tabular}

Note. Means followed by the same capital letter in the column and lowercase in the row do not differ statistically from each other by the Tukey's test at $5 \%$ probability.

The reduction of the surface tension of the drops presents great importance in technology of application of chemical solutions, since it has a direct influence on the spreading of the syrups on the foliar surfaces.

The reduction in studies by Silva-Matte et al. (2014) with adjuvants added to water, it was verified a drop in the surface tension of the droplet, with a better potential of foliar coverage in the application. Based on the results obtained in this study, it was observed that the use of mineral oil in the two syrups was efficient for this function.

In the adaxial side, the use of mineral oil provided a drop spread of 111.8 and $25.7 \%$ higher in relation to the syrups without adjuvant and vegetable oil, respectively. There was no statistically significant difference in the Spreading between the bordeaux syrup and Lime sulfur syrup. Similar behavior was also observed with the use 
of mineral oil in the syrups for the Spreading of the droplet on the abaxial face of the wheat leaves, however, the Lime sulfur syrup drop droplet spread was $4.6 \%$ higher than that of the bordeaux syrup.

In the literature, there are few studies on the use of bordeaux and sulfocaustic syrup mixed with mineral or vegetable oils. However, the results observed in this study corroborate Mendonça, Raetano, and Mendonça (2007) which verified lower surface tension in the grouts with mineral oil $\left(30.4 \mathrm{mN} \mathrm{m}^{-1}\right)$ when compared to vegetable oil $\left(32.8 \mathrm{mN} \mathrm{m}^{-1}\right)$. However, the solutions used by these authors were aqueous.

The results observed in this work, for the spreading of the drops on the adaxial and abaxial faces of the leaves corroborate with the results of the surface tension. For, the smaller tensions in the solutions with addition of the mineral oil promoted the greater spreading. Similar results were also found by Chechetto et al. (2013) to study various adjuvants.

The lower incidence of rust in the wheat plants was verified when the mineral oil was used in the syrups (Table 3). However, the lime sulfur syrup provided $7.8 \%$ less incidence of rust than the use of the bordeaux syrup.

In order to control the leaf smudge, it was verified that the lime sulfur syrup + the mineral oil was the one that presented greater efficiency in relation to the other measured treatments.

Although of being restricted in the literature the use of syrups, bordeaux and lime sulfur in the wheat culture, Carvalho et al. (2010) tested the bordeaux and lime sulfur syrup, with a neutral detergent addition at $0.1 \%$ and they verified efficiency in severity control angular smudge of $75 \%$. The best results observed by these authors may be due to the use of syrups preventively, which was not performed for wheat.

Table 2. Means values of incidence of rust and foliage on wheat plants

\begin{tabular}{lllll}
\hline \multirow{2}{*}{ Syrup } & \multicolumn{4}{c}{ Incidence of rust (\%) } \\
\cline { 2 - 5 } & Without adjuvant & Mineral oil & Vegetable oil & Mean \\
\hline Bordeaux syrup & 11,000 & 8,500 & 10,333 & $9,944 \mathrm{~A}$ \\
Lime sulfur syrup & 10,334 & 7,833 & 9,333 & $9,167 \mathrm{~B}$ \\
\hline Mean & $10,667 \mathrm{a}$ & $8,167 \mathrm{c}$ & $9,833 \mathrm{~b}$ \\
\hline \multirow{2}{*}{ Syrup } & \multicolumn{4}{c}{ Incidence of leaf smudge (\%) } \\
\cline { 2 - 5 } & Without adjuvant & Mineral oil & Vegetable oil & Mean \\
\hline Bordeaux syrup & $9,500 \mathrm{Aa}$ & $6,000 \mathrm{Ab}$ & $6,833 \mathrm{Ab}$ & 7,444 \\
Lime sulfur syrup & $8,333 \mathrm{Ba}$ & $5,167 \mathrm{Bc}$ & $6,500 \mathrm{Ab}$ & 6,667 \\
\hdashline Mean & 8,917 & 5,583 & 6,667 & \\
\hline
\end{tabular}

Note. Means followed by the same capital letter in the column and lowercase in the row do not differ statistically from each other by the Tukey's test at 5\% probability.

The results of the dry mass of the plants corroborate with the results of the incidence of rust and leaf smudge, less diseases plus dry mass (Table 4). No difference between and addition of mineral or vegetable oil and the bordeaux and lime sulfur syrups.

The number of grains per spike with the use of oils, mineral and vegetable in mixture with the bordeaux syrup surpassed the control. However, the use of mineral oil and vegetable oil in the lime sulfur syrup provided 44.1 and $55.2 \%$, respectively, more grains, compared to the control, standing out in production.

There was no difference in the production of grains to the syrup without mixing. However, the lime sulfur mixture with mineral and vegetable oil surpassed the bordeaux mixture by 10.4 and $17.1 \%$, respectively.

For the mass of a thousand grains the mineral oil was more efficient in the mixtures. However, the largest masses were verified with the lime sulfur syrup with the oils, mineral and vegetable, with 9.3 and $13.1 \%$ more mass of one thousand grains, respectively, in relation to the control. 
Table 3. Mean values of dry mass, number of grains per spike and mass of one thousand grains of wheat plants

\begin{tabular}{|c|c|c|c|c|}
\hline \multirow{2}{*}{ Fungicides } & \multicolumn{4}{|c|}{ Dry mass of the plants (aerial part) (g) } \\
\hline & Without adjuvant & Mineral oil & Vegetable oil & Mean \\
\hline Bordeaux syrup & 9,970 & 12,610 & 12,991 & $11,850 \mathrm{~A}$ \\
\hline Lime sulfur syrup & 10,730 & 13,793 & 14,323 & $12,948 \mathrm{~A}$ \\
\hline Mean & $10,350 \mathrm{~b}$ & $13,201 \mathrm{a}$ & $13,657 \mathrm{a}$ & \\
\hline \multirow{2}{*}{ Fungicides } & \multicolumn{4}{|c|}{ Number of seeds per spike (unit.) } \\
\hline & Without adjuvant & Mineral oil & Vegetable oil & Mean \\
\hline Bordeaux syrup & $25,298 \mathrm{Ab}$ & $34,525 \mathrm{Ba}$ & $35,078 \mathrm{Ba}$ & 31,634 \\
\hline Lime sulfur syrup & $26,466 \mathrm{Ac}$ & $38,130 \mathrm{Ab}$ & $41,073 \mathrm{Aa}$ & 35,223 \\
\hline Mean & 25,8825 & 36,3275 & 38,0758 & \\
\hline \multirow{2}{*}{ Fungicides } & \multicolumn{4}{|c|}{ Mass of thousand grains (g) } \\
\hline & Without adjuvant & Mineral oil & Vegetable oil & Mean \\
\hline Bordeaux syrup & $23,031 \mathrm{Bc}$ & $23,738 \mathrm{Bb}$ & $24,855 \mathrm{Ba}$ & 23,875 \\
\hline Lime sulfur syrup & $23,905 \mathrm{Ac}$ & $26,127 \mathrm{Ab}$ & $27,040 \mathrm{Aa}$ & 25,690 \\
\hline Mean & 23,468 & 24,932 & 25,947 & \\
\hline
\end{tabular}

Note. Means followed by the same capital letter in the column and lowercase in the row do not differ statistically from each other by the Tukey's test at 5\% probability.

Both syrups were efficient in disease control, which resulted in the reduction of rust and leaf smudge, however, it is worth stands out the lime sulfur syrup independent of the type of oil used.

Besides that the highest result displayed in the number of grains per spike, mainly with the use of lime sulfur + vegetable oil, may be due to the sulfur contained in this type of syrup, which provided synergistic interaction.

\section{Conclusions}

The greater spreading of the droplets on both leaf faces and the lower incidence of the diseases was provided with the use of lime sulfur syrup + mineral oil.

The use of the adjuvants in the evaluated syrups has positive results in the production components, standing out the mineral oil.

\section{References}

Carvalho, W. P., Wanderley, A. L., \& Oliveira, C. M. (2010). Controle de Mancha-Angular utilizando-se caldas fertiprotetoras em cultivo orgânico de feijoeiro irrigado. Pesquisa Agropecuária Tropical, 40(4), 476-482. https://doi.org/10.5216/pat.v40i4.6264

Chechetto, R. G., Antuniassi, U. R., Mota, A. A. B., Carvalho, F. K., Silva, A. C. A., \& Vilela, C. M. (2013). Influence of spray nozzles and adjuvants in drift reduction potential in wind tunnel. Semina: Ciências Agrárias, 34(1), 37-46. https://doi.org/10.5433/1679-0359.2013v34n1p37

Companhia Nacional de Abastecimento (CONAB). (2017). Acompanhamento da safra brasileira de grãos (p. 160). Brasília: CONAB. Retrieved April 10, 2017, from http://www.conab.gov.br/OlalaCMS/uploads/ arquivos/17_01_11_11_30_39_boletim_graos_janeiro_2017.pdf

Ferreira, D. F. (2011). Sisvar: a computer statistical analysis system. Ciência e Agrotecnologia, 35(6), 1039-1042. https://doi.org/10.1590/S1413-70542011000600001

Lenz, G., Costa, I. F. D., Coradini, C., Dressler, V. L., \& Mellho, P. A. (2011). Disease severity and green leaf area maintenance depending on the application of micronutrients and fungicides in wheat. Summa Phytopathologica, 37(2), 119-124. https://doi.org/10.1590/S0100-54052011000200006

Mendonça, C. G., Raetano, C. G., \& Mendonça, C. G. (2007). Surface tension of mineral oils and vegetable oils. Engenharia Agrícola, 27(Sept.), 16-23. https://doi.org/10.1590/S0100-69162007000200003

Oliveira, G. M., Pereira, D. D., Camargo, L. C. M., Balan, M. G., Canteri, M. G., Igarashi, S., \& Saab, O. J. G. (2013). Control of wheat leaf rust (Puccinia triticina) at different timings of fungicide application. Arquivos do Instituto Biológico, 80(4), 436-441. https://doi.org/10.1590/S1808-16572013000400010 
Rodrigues, G. B., Nakada, P. G., Silva, D. J. H., Dantas, G. G., \& Santos, R. R. H. (2006). Performance of onion cultivars grown in the organic and conventional systems in Minas Gerais State, Brazil. Horticultura Brasileira, 24(2), 206-209. https://doi.org/10.1590/S0102-05362006000200017

Silva-Matte, S. C., Costa, N. V., Pauly, T., Coltro-Roncato, S., Oliveira, A. C., \& Castagnara, D. D. (2014). Variability of breaking the surface tension of the droplet adjuvant (Aureo ${ }^{\circledR}$ ) as a function of local water. Agrarian, 7(24), 264-270.

Souza, B. J. R., Perez, P. H., Bauer, F. C., Raetano, C. G., Weirich, P. H. N., \& Garcia, L. C. (2014). Adjuvants for spraying of fungicides in wheat. Ciência Rural, 44(8), 1398-1403. https://doi.org/10.1590/1809-4430eng.agric.v36n6p1110-1117/2016

Teixeira Neto, E., Malta, M. M., \& Santos, R. G. (2009). Surface tension measurement by drop counting method: method description and experiments with etoxilated non-ionic surfactants. Quimica Nova, 32(1), 223-227. https://doi.org/10.1590/S0100-40422009000100037

Tormen, N. R., Lenz, G., MinuzzI, S. G., Uebel, J. D., Cezar, H. S., \& Balardin, R. S. (2013). Reaction of wheat cultivars to leaf rust and yellow spot and responsiveness to fungicides. Ciência Rural, 43(2), 239-246. https://doi.org/10.1590/S0103-84782013000200008

Vale, F. X. R., Fernandes Filho, E. I., \& Liberato, J. R. (2003). Quant: A software plant disease severity assessment. In 8th International Congress of Plant Pathology, 2003, New Zeland. Anais eletrônicos... New Zeland: Christchurch. Retrieved April 19, 2017, from http://www.scielo.br/scielo.php?script=sci_nlinks\&ref $=000055 \& \mathrm{pid}=\mathrm{S} 0100-5405201000020001000008 \& \operatorname{lng}=\mathrm{en}$

\section{Copyrights}

Copyright for this article is retained by the author(s), with first publication rights granted to the journal.

This is an open-access article distributed under the terms and conditions of the Creative Commons Attribution license (http://creativecommons.org/licenses/by/4.0/). 